Portland State University

PDXScholar

Engineering and Technology Management

Faculty Publications and Presentations

$10-8-2018$

\title{
Organizational Project Management (OPM): Exploring Its Need in Organizations
}

\author{
Yaser Alnasri \\ Portland State University \\ Jeffrey S. Busch \\ Portland State University
}

Follow this and additional works at: https://pdxscholar.library.pdx.edu/etm_fac

Part of the Engineering Commons

Let us know how access to this document benefits you.

\section{Citation Details}

Y. Alnasri and J. S. Busch, "Organizational Project Management (OPM): Exploring Its Need in Organizations," 2018 Portland International Conference on Management of Engineering and Technology (PICMET), Honolulu, HI, 2018, pp. 1-6.

This Article is brought to you for free and open access. It has been accepted for inclusion in Engineering and Technology Management Faculty Publications and Presentations by an authorized administrator of PDXScholar. Please contact us if we can make this document more accessible: pdxscholar@pdx.edu. 


\title{
Organizational Project Management (OPM): Exploring Its Need in Organizations
}

\author{
Yaser Alnasri, Jeffrey S. Busch \\ Dept. of Engineering \& Technology Management, Portland State University, Portland, Oregon, USA
}

\begin{abstract}
Organizational Project Management (OPM) is not a "thing" or a "procedure" rather, it can almost be described as a "state of being" or "harmony" in the alignment of what an organization does and how it gets there. OPM has the responsibility to enhance and improve how an organization achieves its strategic goals. It provides organizations with an intelligent approach to deal effectively with the various projects and programs required by the market, its organizational stakeholders, and regulatory agencies, all within the organization's limited resources. OPM has the responsibility to support the alignment between the organization's business strategy and its projects to achieve the organization's goals. It is also responsible for managing risks and dealing with the uncertainty that may prevent the organization from achieving its objectives. In addition, it enables the organization to measure its capabilities, then plan and implement improvements to seek the systematic achievement of best practices. Moreover, it ensures organizational learnings from both knowledge management and lessons learned.

The purpose of the research is to illustrate the important role that OPM must or needs to play within the organization. This research utilizes the current knowledge base in the project management environment to answer the question of "Why does an organization need to establish OPM?" In addition to describing OPM's responsibility in the organization, the paper will briefly explore four categories, Portfolio Management, Project Sponsor, Effective Programs and Projects Management, and Strategic Project Management Office (PMO) for establishing OPM in an organization.
\end{abstract}

\section{INTRODUCTION: WHY OPM?}

Organizations adopt project management practices to achieve business objectives and create value. However, the success or failure of projects is not solely dependent on the project manager or the project team [1]. Factors like organizational culture, structure, and governance are not under project manager control, yet they affect the outcomes of projects. Research has found that many projects do not deliver their expected value within their budget and time span because they are not aligned to the strategic goals of the organization or because they lack the support from senior and executive managements [2]. A study by the Project Management Institute (PMI) found that "organizations that align their overall strategies with their program and project portfolios are more likely to have programs and projects that meet schedule, scope, quality, budget, and business benefits requirements" [3]. Organizations that deal with numerous projects usually have two management functions. [4]. The first function is accountability for delivering project execution, what we call the project management function. This accountability includes standardizing the project management practices across the organization and providing support for the project managers in order to increase the success of the projects. The second function is the role of senior and executive management which is responsible for setting the strategic goals of the organization and ensuring that they can be met by providing the executive and financial sponsorship support. This responsibility includes ensuring that projects are aligned to the organization's strategic goals and that benefits for the organization are realized.

When choosing projects, senior and executive managers aim to select projects that most likely support the objectives of the organization. However, the problem is often the lack of alignment between the executive management function and the project management function. This lack of alignment can result in the organization's objectives that are not well communicated to the project management function, and project decisions being made for projects that are not related to those objectives [5] [6] [7]. Four categories of OPM practices are explored in an effort to describe how organizations are attempting to comprehensively align with OPM. The authors have added a fifth category, that they have labeled as a default approach where organizations do not follow an established approach and simply go with what they have in place. The project management function usually measures the success of projects by delivering their scope within their schedule and cost. Nevertheless, the market shifts and project objectives may change. Thus, selected projects need to be periodically reviewed and measured against the objectives of the organization. Do these projects still carry the benefits to the strategic goals of the organizations? What should the project management function know about the project objectives to help balance the schedule, cost, and scope of projects? These basic questions need timely responses. Herein exists the opportunity for the role and responsibility of OPM to serve as the interface for the organizational need and to bridge the gaps that are between the executives and project management.

\section{LITERATURE REVIEW}

A particular hurdle that was faced when conducting the literature review was the apparent lack of literature that primarily focused on OPM. Much of the literature circled OPM by blending it with known practices in the Project Management, such as Portfolio Management or Project 
Management Offices. The literature on the importance of implementing project management practices to achieve the project goals is a plethora. However, Organization Project Management (OPM) is a topic that in the author's opinion still lacks research on its importance for organizations to achieve their goals. Organizational interviews were attempted with many organizations but faced the problem that the organizations had no defined structure of OPM, and that responsibility of OPM was not assigned to a person or a group. Thus, we have reviewed the papers written about the OPM field in order to answer the question of "Why does an organization need to establish OPM?" This paper summarizes the conclusion of extensive research for the OPM field of study.

The sections that follow Challenges in Establishing OPM address the literature review and the attempts by various authors to effectively describe OPM. The outcome of this research is an interpretation of these various and sometimes wide perspectives on the topic and how application is practiced. Four categories of OPM practices are described in those sections.

\section{DEFINITION OF OPM}

There are variations in the definition of OPM. One definition is "the application of knowledge, skills, tool and techniques to organizational and project activities to achieve the aims of an organization through projects" [10]. OPM is also defined as "a new sphere of management where dynamic structures in the firm are articulated as a means to implement corporate objectives through projects in order to maximize value" [11]. In addition, the Project Management Institute (PMI) defines OPM as "a strategy execution framework utilizing project, program, and portfolio management as well as organizational enabling practices to consistently and predictably deliver organizational strategy producing better performance, better results, and sustainable competitive advantage" [10]. Almost all OPM definitions agree on the fact that it enhances and improves what an organization does. However, they differ in the way they describe what OPM is.

Some definitions describe OPM as a structured framework or as a defined process. This variation in the definition is due to the fact that OPM is not a unique model to manage organizational strategies [11]. It is not a framework that organizations can adapt to solve their problems. OPM is essentially a "responsibility." and touches a broad spectrum across organizations. This responsibility includes alignment between the project management and the business strategy. It may also be responsible for standardizing of project management practices, risk management, organizational learning, and stakeholders' management. Therefore, this research proposes a universal definition for OPM as a "responsibility" of the organization to enhance and improve what an organization does to ensure the achievement of its strategic goals.

In establishing OPM, it's important that organizations have the fundamental elements for managing projects in place including governance, competency, process, and culture [12]. The term governance encompasses that management should ensure that projects are aligned with strategic goals and that policies for managing the portfolios, programs, and projects are established. Competency refers to upgrading the project management competency, including all the developmental activities such as training, coaching, and mentoring. Process refers to standardizing the methodologies and tools for managing projects across the organization. Culture refers to enforcing an environment of project management practices, standardizing, mentoring, expanding experiences, and lessons learned. Combining these elements closely resembles the organization's project management maturity.

OPM is easily more suitable for organizations that have the foundation of project management in place, and try to become better in aligning their projects to their strategic goals. However, organizations that do not have a project management foundation need to self-assess its applications and benefits of project success through project management. Literature on the importance of project management practices is plethora; however that topic is out of the scope for this research.

\section{ChALLENGES IN ESTABLISHING OPM}

Establishing OPM is challenging because there is no one methodology or framework for doing so. OPM establishment varies from one organization to another depending on a number of factors, including the organizational structure, size, industry sector, target, and the level of its maturity in project management. In addition, the establishment of OPM may face a strong resistance from departmental managers as it may add more constraints to how they manage their departments.

Literature on the procedures and standards for effective OPM can be classified into four categories of practices. These categories are Portfolio Management, Project Sponsors, Effective Programs and Projects Management, and Strategic Project Management Office (strategic PMO) [13]. This research is labeling a fifth category as "do nothing and hope it works," as the default OPM approach. The following discusses these categories.

\section{PORTFOLIO MANAGEMENT}

Portfolio management is seen as one category to establish OPM and is defined as the process of identifying, prioritizing, authorizing, managing, and controlling projects and programs in order to achieve specific strategic business objectives [14]. It works as a framework to ensure a balance of candidate projects that achieve the maximum benefits within the limited resources of the organization [15] [16] [17]. It also assists in having an appropriate mix of high-risk high return projects that support the future of the organization, and low-risk projects with a short payback period that are necessary to keep operations going [13]. The organization's missions, objectives, goals, and strategies are transformed into programs, which are 
broken down into projects. These projects become part of the organization's portfolio. This process ensures that projects contribute to the organization's overall goals [12]. Besides making sure that projects support the organization's objectives, project portfolio management enables managers to understand the big picture of how projects fit into the strategic direction of the organization. This facilitates sorting, adding, and removing projects based on the best interest of the organization. It also helps in sizing up the competing investment opportunities and prioritizing projects that promise the greatest impact on the business strategy [18].

Portfolio management can support the establishment of OPM by ensuring the achievement of the organization's business strategy through selecting the right projects and programs to initiate or continue to deliver success [4]. Typically, projects have to pass three criteria: Fit, Utility, and Balance (FUB) to be considered in the portfolio of the organization [12]. Fit means that projects have to be aligned to the overall strategic goals. Utility means they must add value. Balance refers to balancing the mix of projects in the portfolio. It also includes killing projects that are no longer in line with the organization's business strategy or the market need, and alters these resources to those that contribute to the strategic plan or be in need for additional support [19].

\section{PROJECT SPONSORS}

Top management support is considered to be one of the main factors for project success or failure [20]. However, not all project managers can have a strong interaction with senior management. Therefore, the project sponsor functions as a critical link between top-level management and the project management team. [21]. Project sponsorship is seen as a second category for establishing OPM and is defined as "A person or group who provides resources and support for the project, program, or portfolio and is accountable for enabling success" [10]. Research has demonstrated that the capabilities of the project sponsor have a crucial impact on the project performance [21] [22]. The project sponsor can support and sponsor the implementation and the establishment of OPM by defining business requirements, approving the project objectives and success criteria, monitoring the business environment, and ensuring benefit realization. Project sponsors are also responsible for supporting the project manager and the project team in making decisions or recommendations at critical points in the project's life [22]. They are accountable to top-level management for ensuring that benefits for the organization are realized [13]. Nevertheless, studies have proven that the concept of project sponsoring is very challenging and confusing in practice [23].

\section{EFFeCtive Program AND ProJeCts MANAGEMENT}

Since programs and projects are the instruments to achieve the organization's strategic goals, a management "by projects" approach should be enforced in organizations [24]. Effective program and projects management is the third category to establishing OPM through a 'project' approach. This approach delegates the governance of projects to the program or project managers. Hence, the program or project managers may be fully responsible for [13]:

- $\quad$ authorizing the start of projects

- authorizing changes to the project

- ensuring that projects are in line with the organization's policies and any relevant legal or regulatory requirements

- ensuring that managerial and technical oversight is maintained

- making sure that projects meet the organization's strategic goals

- making sure that user needs and expectations are being met

- ensuring that the program/project remains viable and business need is being addressed

- managing the project on a daily basis

However, delegating the governance functions to all project or program managers can be challenging to implement in organizations that deal with many projects, as it requires that all project managers be involved in the executive level where the strategic goals of the organization are developed.

\section{Strategic Project Management Office}

Most of the existing research on the application of a strategic Project Management Offices (PMO) focusses on its benefits toward project performance. However, there is not much literature that discusses the relationship between the strategic PMO and the organization's strategic goals [25] [26]. This section focuses on how a strategic PMO can function as an instrument to support the establishment of OPM in an organization. As was previously described, OPM is a responsibility of the organization to enhance and improve what an organization does to ensure the achievement of its strategic goals. The strategic PMO is a concept that enables organizations to effectively fit and successfully establish OPM [9]. It utilizes the organization's resources to fill the gap between having knowledge of OPM and the realization of its benefits. The strategic PMO supports the establishment of OPM by [3]:

- carrying the responsibility for aligning the portfolio of programs and projects to the business strategy

- standardizing and customizing program and project management practices

- enhancing governance and accountability

- optimizing the investment of the portfolio of programs and projects

- managing talent and developing resources

- ensuring stakeholder buy-in

- driving the required change in the organization

- proactively managing risk

- serving as a resource and knowledge repository for project management 
In other words, the strategic PMO becomes responsible for doing the right projects the right way.

\section{DEFAULT OPM APPROACH}

Organizations that do not follow an established approach for OPM are prone to default and they hope it works. This means they try to do their best in aligning their projects to the strategic goals of the organizations. As an example, organizations often assume that:

- project managers will know how to deliver a successful project

- department managers will oversee and create processes

- everyone knows what the strategic goals are and how to get there

- the market will not change too fast

- projects will carry forward the strategic objectives of the organization

These organizations may be assuming certain answers to the preverbal question or intimidated by what it might cost. In other words, why do they need OPM and why doesn't it just work automatically? These organizations often find that they are in a constant state of flux and crisis management.

\section{BENEFITS OF ESTABLISHING OPM}

OPM is a responsibility and with that responsibility comes the understanding that OPM touches and should be responsive to the many components of an organization. These components include business strategy, project management practices, risk management, organizational learning, and stakeholders buy-in. The following discusses these components and the benefits achieved through OPM.

\section{Alignment of Project Management with the BUSINESS STRATEGY}

Organizations are constantly looking to develop innovative business strategies to remain viable in today's competitive market. These business strategies are usually developed by executives and top-level managers. However, top-level managers do not necessarily have a strong effect on the operational level of the organization where projects are conducted, resulting in projects that are not aligned to the strategic goal of the organization. OPM helps the organization to align its projects with its strategic goals by providing boundaries on which projects should be approved, funded and supported. This alignment helps to achieve the goals of the business strategies and the benefits of the projects [27]. As shown in Figure 1 below, OPM links the organizational strategic goals through its portfolios, programs, projects, deliverables, and tasks to ensure the optimal realization of the strategic benefits.

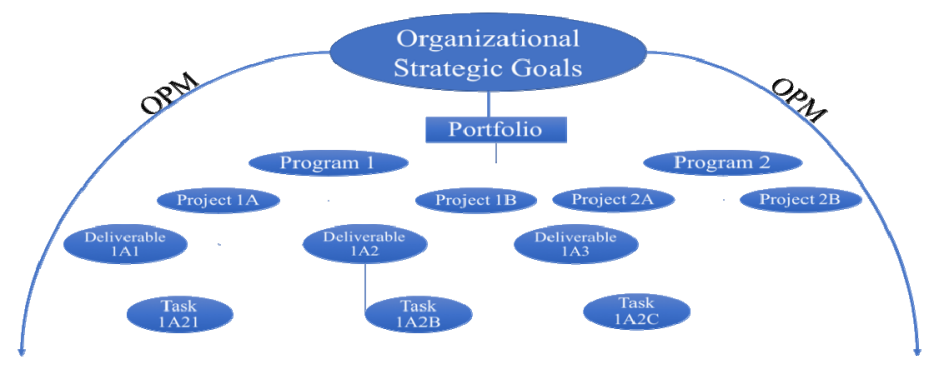

Figure 1. OPM Alignment

OPM also supports the alignment between the project management elements and an organization's competitive attributes [7]. For instance, when an organization selects timeto-market to be its competitive attribute, OPM becomes responsible for aligning its project management elements, strategy, organization, process, tools, metrics, and culture, to accomplish this attribute. This is done by creating a scheduledriven environment and tailoring the project management elements such as process and tools to be more flexible in order to support the organization's competitive attribute. Creating a time-to-market culture, allows project managers to favor the schedule over the cost or product features when making tradeoff decisions. On the other hand, if the organization's competitive attribute is cost leadership, OPM helps in creating a cost-saving environment. Elements such as tools and metrics are tailored to be more standardized in order to reduce the cost.

\section{Standardized Project Management Practices}

OPM helps organizations in promoting and applying the best practices and guidelines for managing various levels of projects. It is responsible for defining PM roles, setting expectations, and standardizing program and project management practices in order to improve and achieve consistent results from projects and the execution of the business processes [28]. Common templates and tools provide consistency for both project managers and team members across the organization. It also helps in establishing a common language among all employees of the organization. This can be very helpful, as most all strategic driven projects are delivered cross-functionally. They also facilitate the process of onboarding new project managers or new team members. Project management standardization is often viewed as a component of the PMO's operational practices.

\section{MANAGED RISK}

PMI defines risk as "An uncertain event or condition that, if it occurs, has a positive or negative effect on a project's objectives" [29]. Risk management enables organizations to look out ahead of the curve, identify and address coming threats or opportunities to achieve project success [30]. According to PMI's 2017 report, only 60 percent of organizations apply risk management practices [31]. OPM creates a culture of proactive risk management by identifying, 
assessing, and controlling threats and opportunities in the projects, programs, and portfolio environment. This helps in establishing an integrated approach to risk management to support the organization in delivering value and gaining competitive advantages [31].

\section{MANAGED ORGANIZATIONAL LEARNING}

Organizational learning is defined as "the process of creating, retaining, and transferring knowledge within an organization [32]." OPM helps organizations to manage project documentation archives; conduct post project reviews; conduct project audits; and manage database on lessons learned [33]. This process measures organizational capability in order to advance the organizational learning where needed. Although capability measurement might not seem to have a big influence and many organizations tend to neglect it; it is a very crucial element to make sure that strategic projects are done right. Peter Drucker has said: "What gets measured gets done, what gets measured and fed back gets done well, what gets rewarded gets repeated" [12]. An established OPM can embed organizational learning from past projects to prevent repeating the mistakes from previous projects and increasing the chances of future project success [34] [35] [36].

\section{ENSURED STAKEHOLDER BUY-IN}

Lack of stakeholder buy-in is considered to be one of the most common reasons for project failures [12]. Even though project managers are often responsible for dealing with stakeholders, they can use the added support and organizational backup when working with difficult stakeholders. OPM can serve in this capacity by establishing an integrated approach to stakeholder management. OPM is also responsible for dealing with the organizational relationship issues; including power, politics, influence, special interest, hidden agendas, and interpersonal conflicts [12]. The process of stakeholder management requires a lot of effort and time. However, it is a crucial element for the project success.

\section{RESEARCH RESULTS AND FINDINGS}

Briefly, it was found that OPM has the responsibility to enhance and improve how an organization achieves its strategic goals. It provides organizations with an intelligent approach to deal effectively with the various projects and programs required by the market, its organizational stakeholders, and regularity agencies, all within the organization's limited resources. OPM has the responsibility to support the alignment between the organization's business strategy and its projects to achieve the organization's goals. It is also responsible for managing risks and dealing with the uncertainty that may prevent the organization from achieving its objectives. In addition, it enables the organization to seek out improvements to their practices and to ensure organizational learning.
The contribution of this research identifies that OPM is not well understood and comes with a variety of interpretations that may be complimentary to each other, but lack a clear and concise definition across industry sectors. Findings are consistent with the existing and current literature, such that the practical and theoretical implications of OPM need further research and publications. Conflict of OPM interpretations within existing research will exist and could point to a more global and exacting definition and practice. The significance of this paper is probably better conveyed by the limitations discovered in the research that lead to multiple crossroads of future qualitative research and direction.

\section{CONCLUSION}

The research investigated the categories of practice for establishing OPM, as Portfolio Management, Project Sponsor, Effective Programs and Projects Management, and Strategic PMO. Without an approach to establishing OPM, organizations are prone to default and hope it works. This research defined OPM as a responsibility of the organization to enhance and improve what an organization does to ensure the achievement of its strategic goals through successful project delivery.

OPM should provide organizations with an intelligent approach to link and align the many organizational and integrative aspects of portfolio, programs, and projects. It should support the alignment between the organization's business strategy and its projects to achieve the organization's goals. It should help organizations manage the risks and deal with the uncertainty that may prevent the organization from achieving its objectives. In addition, it enables the organization to measure its capabilities, then plan and implement improvements to seek the systematic achievement of best practices. Moreover, it ensures organizational learnings from both knowledge management and lessons learned. And, most importantly, it should allow organizations to evolve, grow and adapt to the changing business environment.

Future research opportunities exist to pressure organizations for their participation in OPM surveys and interviews to help validate the findings presented in this paper and for corroborating known structured approaches in practice. Precise details on 'how' structured approaches to OPM are practiced would also be discovered by case studies of OPM successes, frustrations, hurdles and barriers to success.

\section{REFERENCES}

[1] [1] L. Crawford, T. Cooke-Davies, B. Hobbs, L. Labuschagne, K. Remington and P. Chen, "Governance and support in the sponsoring of projects and programs," Project Management Journal, vol. 39, no. 1, pp. S43-S55, 2008.

[2] [2] T. Knodel, "Preparing the organizational 'soil' formeasurable and sustainablechange: business value management and project governance," Journal of Change Management, vol. 4, no. 1, pp. 45-62, 2004.

[3] [3] L. Bull, K. Shaw, and C. Baca, "Delivering strategy: organizational project management and the strategic PMO," in PMI® Global Congress, 
2012, North America, Vancouver, British Columbia, Canada. Newtown Square, PA: Project Management Institute, 2012.

[4] [4] H. Levine, Project portfolio management: A Practical Guide to Selecting Projects, Managing Portfolios, and Maximizing Benefits. San Francisco, CA: Jossey-Bass Inc., 2005.

[5] [5] S. Srivannaboon, "Linking project management with business strategy," in PMI® Global Congress, 2006, North America, Seattle, WA. Newtown Square, PA: Project Management Institute, 2006.

[6] [6] P. Dietrich and P. Lehtonen, "Successful management of strategic intentions through multiple projects - Reflections from empirical study," International Journal of Project Management, vol. 23, no. 5, pp. 386-391, 2005.

[7] [7] S. Srivannaboon and D. Milosevic, "A two-way influence between business strategy and project management," International Journal of Project Management, vol. 24, no. 6, pp. 493-505, 2006.

[8] [8] C. Baca, L. Bull, T. C. Davies and S. Porskrog, "OPM3®—the path to organizational achievement of strategic business improvement," in PMI® Global Congress, 2007, North America, Atlanta, GA. Newtown Square, PA: Project Management Institute, 2007.

[9] [9] M. Aubry, B. Hobbs and D. Thuillier, "A new framework for understanding organisational project management through the PMO," International Journal of Project Management, vol. 25, no. 4, pp. 328-336, 2007.

[10] [10] A Guide to the Project Management Body of Knowledge (PMBOK® Guide), 5th ed. Newtown Square, PA: Project Management Institute, 2012.

[11] [11] V. Anyosa Soca, "Linking portfolio, program, and projects to business strategy: a way to gain competitive advantage in this turbulent time," in PMI® Global Congress, 2009, North America, Orlando, FL. Newtown Square, PA: Project Management Institute, 2009.

[12] [12] P. Dinsmore and L. Rocha, Enterprise Project Governance: A Guide to the Successful Management of Projects Across the Organization. New York: American Management Association, 2012.

[13] [13] E. Too and P. Weaver, "The management of project management: A conceptual framework for project governance," International Journal of Project Management, vol. 32, no. 8, pp. 1382-1394, 2014.

[14] [14] D. Ross and P. Shaltry, "The new PMI standard for portfolio management," in PMI® Global Congress, 2006, Madrid, Spain. Newtown Square, PA: Project Management Institute, 2006.

[15] [15] The standard for portfolio management, 2nd ed. Newtown Square, PA: Project Management Institute, 2008.

[16] [16] D. Miloéseviâc, Project Management Toolbox - Tools and Techniques for the Practicing Project Manager, 1st ed. Hoboken, New Jersey: John Wiley \& Sons, 2003.

[17] [17] R. Vargas, "Using the analytic hierarchy process (AHP) to select and prioritize projects in a portfolio," in PMI® Global Congress, 2010, North America, Washington, DC. Newtown Square, PA: Project Management Institute, 2010.

[18] [18] P. Dinsmore and T. Cooke-Davies, Right projects done right: From Business Strategy to Successful Project Implementation. San Francisco: Jossey-Bass, 2006

[19] [19] S. Elonen and K. Artto, "Problems in managing internal development projects in multi-project environments," International Journal of Project Management, vol. 21, no. 6, pp. 395-402, 2003.
[20] [20] B. Unger, A. Kock, H. Gemünden and D. Jonas, "Enforcing strategic fit of project portfolios by project termination: An empirical study on senior management involvement," International Journal of Project Management, vol. 30, no. 6, pp. 675-685, 2012.

[21] [21] L. Labuschagne, T. Cooke-Davies, L. Crawford, J. Hobbs, and K. Remington, "Exploring the role of the project sponsor," in PMI® Global Congress, 2006, North America, Seattle, WA. Newtown Square, PA: Project Management Institute, 2006.

[22] [22] J. Turner, The Handbook of project-based management: Leading Strategic Change in Organizations, 3rd ed. New York: McGraw-Hill, 2009.

[23] [23] A. Sense, "A project sponsor's impact on practice-based learning within projects," International Journal of Project Management, vol. 31, no. 2, pp. 264-271, 2013.

[24] [24] D. Rezania and T. Lingham, "Coaching IT project teams: a design toolkit," International Journal of Managing Projects in Business, vol. 2, no. 4, pp. 577-590, 2009.

[25] [25] P. Dietrich, K. Artto, and J. Kujala, "Strategic priorities and PMO functions in project-based firms," in PMI® Research Conference, Defining the Future of Project Management, 2010, Washington, DC. Newtown Square, PA: Project Management Institute, 2010.

[26] [26] M. Hurt and J. Thomas, "Building value through sustainable project management offices," Project Management Journal, vol. 40, no. 1, pp. 55-72, 2009

[27] [27] R. Ansari, E. Shakeri and A. Raddadi, "Framework for Aligning Project Management with Organizational Strategies," Journal of Management in Engineering, vol. 31, no. 4, p. 04014050, 2015.

[28] [28] G. Strausser and S. Barney, "Implementing organizational project management (OPM) maturity: the good, the bad, and the ugly," in $P M I \circledR$ Global Congress, 2011, EMEA, Dublin, Leinster, Ireland. Newtown Square, PA: Project Management Institute, 2011.

[29] [29] A guide to the project management body of knowledge (PMBOK guide), 3rd ed. Newtown Square, PA: Project Management Institute, 2004

[30] [30] D. Hulett, "What every executive needs to know about project risk management," in Project Management Institute Annual Seminars \& Symposium, 2002, San Antonio, TX. Newtown Square, PA: Project Management Institute, 2002.

[31] [31] A. Strazmesterov, "What Could Go Wrong?" PM Network, vol. 31, no. 8, pp. 26-27, 2017.

[32] [32] L. Argote, Organizational Learning, 2nd ed. Boston, MA: Springer US, 2013.

[33] [33] M. Aubry, M. Richer, M. Lavoie-Tremblay and G. Cyr, "Pluralism in PMO performance: The case of a PMO dedicated to a major organizational transformation," Project Management Journal, vol. 42, no. 6 , pp. 60-77, 2011.

[34] [34] T. Kotnour, "A learning framework for project management," Project Management Journal, vol. 30, no. 2, pp. 32-38, 1999.

[35] [35] B. Levitt and J. March, "Organizational Learning," Annual Review of Sociology, vol. 14, no. 1, pp. 319-340, 1988.

[36] [36] J. March, "Exploration and Exploitation in Organizational Learning," Organization Science, vol. 2, no. 1, pp. 71-87, 1991. 